\title{
The effects of nasogastric feeding at different intervals on feeding intolerance in ICU patients: a single-blind, randomized, controlled trial
}

KHODAYAR OSHVANDI ${ }^{1, A, D-F}$, FAZEL DEHVAN ${ }^{2, A, E}$, GHOLAMHOSEIN FALAHINIA ${ }^{3, A, ~ D-F}$, ORCID ID: 0000-0002-2224-8870

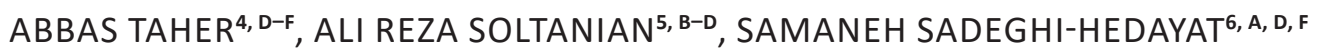

${ }^{1}$ Mother and Child Care Research Center, School of Nursing and Midwifery, Hamadan University of Medical Sciences, Hamadan, Iran

${ }^{2}$ Clinical Care Research Center, Kurdistan University of Medical Sciences, Sanandaj, Iran

${ }^{3}$ Chronic Diseases (Home Care) Research Center, Hamadan University of Medical Sciences, Hamadan, Iran

${ }^{4}$ Department of Anesthesiology, School of Medicine, Hamadan University of Medical Sciences, Hamadan, Iran

${ }^{5}$ Department of Biostatistics and Epidemiology, School of Health, Hamadan University of Medical Sciences,

Hamadan, Iran

${ }^{6}$ Department of Medical-Surgical Nursing, School of Nursing and Midwifery, Hamadan University of Medical Sciences, Hamadan, Iran

A - Study Design, B - Data Collection, C - Statistical Analysis, D - Data Interpretation, E - Manuscript Preparation, F - Literature Search, G - Funds Collection

Summary Background. Most patients hospitalized in intensive care units (ICUs) are fed through a feeding tube. Intolerance is one of the most common complications of tube feeding, and it is observed in more than half of these patients. Each of the tube feeding methods has some advantages and disadvantages, which require more extensive research in order to confirm the proper method for nutrition.

Objectives. This study was conducted to compare nasogastric feeding at different intervals on the feeding tolerance of ICU patients. Material and methods. Sixty-three patients hospitalized in the ICU of Besat Hospital in Hamadan, Iran who were undergoing tube feeding by the bolus method participated in this single-blind, randomized, clinical trial. The patients were randomly divided into three groups of 21 people each and were administered bolus feeding in intervals of 2, 3, and 4 hours. The feeding intolerance (regurgitation, diarrhea, and high gastric residual volume) were assessed and compared with each other according to a checklist for three consecutive days.

Results. Regurgitation accrued in $66.7 \%(n=14), 38.1 \%(n=8)$, and $23.8 \%(n=5)$ of patients fed every 2,3 , and 4 hours, respectively; these differences were statistically significant $(p=0.017)$. The gastric residual volume was $61.9 \%(n=13), 38.1 \%(n=8)$, and $23.8 \%$ $(n=5)$ in the three groups, which was also a statistically significant difference $(p=0.04)$, but in the case of diarrhea, no significant difference was observed among the three groups $(p=0.14)$.

Conclusions. The interval of every 4 hours demonstrated a low risk of gastrointestinal complications, so it is suggested for use with patients in the ICU as the safest mode from the different intervals tested.

Key words: feeding methods, enteral nutrition, Intensive Care Unit.

Oshvandi K, Dehvan F, Falahinia G, Taher A, Soltanian AR, Sadeghi-Hedayat S. The effects of nasogastric feeding at different intervals on feeding intolerance in ICU patients: a single-blind, randomized, controlled trial. Fam Med Prim Care Rev 2020; 22(2): 140-145, doi: https://doi.org/10.5114/fmpcr.2020.95322.

\section{Background}

Nutrition is one of the basic human needs which is important for people in terms of promoting health and preventing diseases [1]; such importance is more commonly highlighted for patients who are hospitalized in intensive care units (ICUs) [2]. Critically ill patients experience important metabolic changes in the course of their disease, changes which have profound effects on their nutritional status. In these patients, the metabolic response to stress and damage will increase the release of cytokines and certain hormones, such as catecholamine, glucagon, cortisol, and growth hormone. These hormones induce catabolism and overcome the anabolic effects of insulin; they cause hyper-metabolism, hyper-catabolism, and a loss of the body's energy reserves $[3,4]$.
Malnutrition is one of the conventional problems in acute diseases, which occurs in more than $40 \%$ of hospitalized patients and has a higher prevalence among ICU patients [5-7]. Malnutrition leads to increased rates of infection, delayed wound healing, bacteria growth in the digestive system, a loss of nutrients via the stool, a loss of respiratory muscle mass, increased dependence on mechanical ventilation, sepsis, increased length of hospital stay, increased mortality rate, and increased treatment costs [8-10]. Therefore, it is essential to support the nutritional needs of these patients.

Nutritional support is provided by tube or by intravenous methods. In patients whose gastrointestinal tract is functioning and who are simply unable to eat through their mouth, tube feeding is preferred over intravenous feeding because it is much closer to physiological conditions, prevents infection, and is costeffective. However, there are several factors which can poten- 
tially limit tube feeding, such as feeding intolerance, movement or obstruction of the feeding tube, and nutritional interference with diagnostic and therapeutic procedures and tests. Feeding intolerance, including high gastric residual volume, nausea, vomiting, and diarrhea, are the main limiting factors for food intake [11, 12]. Studies have shown that the number of hospitalization days in the ICU, the number of days with mechanical ventilation, and the mortality rate are higher in patients who experience feeding intolerance symptoms than in other patients $[10,13]$.

In tube feeding, the three methods which are typically used are intermittent bolus, intermittent drip, and continuous drip [14]. Studies have shown that each of these methods presents some advantages and some disadvantages. For example, Kadamani et al. examined the incidence of aspiration and gastrointestinal complications among critically ill patients undergoing tube feeding by continuous and bolus methods and concluded that there was no statistically significant difference in the incidence of vomiting, increased gastric residual volume, or pulmonary aspiration between these two feeding methods. However, the incidence of diarrhea was higher with the bolus feeding method and constipation was higher with the continuous feeding method [15]. In another study, Bowling et al. investigated the effect of nasogastric feeding using the bolus and continuous methods in gastroesophageal reflux disease (GERD) - and emptying the stomachs of healthy volunteers - and found no statistically significant difference between the different feeding methods in terms of the incidence of complications among the healthy controls [16]. Büyükçoban et al. compared two different enteral nutrition protocols in critically ill patients and found a significant difference in the rate of gastrointestinal intolerance between two groups, reporting a lower gastrointestinal intolerance rate for a 4-hour bolus interval protocol (Group 1) than for an 8-hour protocol (Group 2) [17]. As shown by the results of these studies, there are some inconsistencies in the findings which require more extensive research in order to confirm the most appropriate nutrition method for patients hospitalized in ICUs.

According to the literature, most of the studies carried out on tube feeding methods deal with a comparison of bolus feeding and continuous methods; not many studies have been conducted on the time interval of bolus feeding in order to reduce complications. Considering the fact that the feeding method used in most Iranian hospitals today is bolus feeding at a 3-hour interval [18], the authors hypothesize that a 2-hour or 4-hour interval may be superior to the usual 3-hour interval in reducing complications.

\section{Objectives}

The aim of this study was to assess the effect of nasogastric feeding at different intervals on feeding tolerance among ICU patients.

\section{Material and methods}

\section{Study design}

This study was a 3-group clinical trial.

\section{Participants}

The research population included all of the patients hospitalized in the ICU of Besat Hospital, Hamadan, in western Iran. The ICU has 28 beds; the patients are visited daily by general surgical, internal medicine, and critical care specialists.

From 98 patients hospitalized in the ICU who underwent nasogastric feeding, 63 patients met the inclusion criteria and were selected to participate in the study (Table 1).

The inclusion criteria were as follows: an age of 18 years or more [19]; nasogastric feeding by the bolus method for at least three days of admission in the ICU according to a physician's or- der; a Glasgow Coma Scale (GCS) score of less than 11; no history of diabetes, liver failure, or renal failure (due to the need for a special diet); no immunosuppressive diseases or use of immunosuppressing drugs; no gastrointestinal diseases or surgery during the previous six weeks [20]; no addiction to drugs or use of drugs which increase gastrointestinal motility [19]; and no diarrhea prior to the study [21]. The exclusion criteria were use of drugs that enhance gastrointestinal motility; a residual volume greater than $200 \mathrm{ml}$ [2]; gastrointestinal complications due to reasons other than the patient's intolerance; and patient's transfer from the ICU to another ward. The tools used in this study included a checklist for recording nutritional status and a form for recording which drugs were administered.

$n=\frac{2\left(z 1-\frac{\alpha}{2}+z 1-\beta\right)^{2} \delta^{2}}{(\Delta \mu)^{2}}=\frac{2(1.96+1.64)^{2} 5.85^{2}}{5^{2}}=21$

$1.64=Z 1-\beta, 1.96=\underline{Z} 1-\alpha / 2,5 \mathrm{~mm}=\Delta \mu=\mu i-\mu j, \delta 2=5.85$.

\section{Sampling method}

The sampling was performed using the convenience sampling method, and the patients were divided into three groups. Once the proposed study was approved, the researcher assessed the patients, and after verifying that they met the inclusion criteria, obtained written consent from the patient or their guardian/family member. The number of calories required for each patient was calculated using the formula $25 \mathrm{kcal} / \mathrm{kg} / \mathrm{day}$ [22]. Before entering the study, disease intensity and consciousness levels were assessed by the Acute Physiology and Chronic Health Evaluation (APACHE) II and GCS scales, respectively. The food formula and feeding method used were similar in all three groups. The food formula was standard Ensure powdered formula made in Germany and the feeding method was bolus feeding with a no. 18 Nasogastric tube. The first, second, and third groups were fed a volume of $200 \mathrm{ml}$ every $2 \mathrm{hr}, 300 \mathrm{ml}$ every 3 $\mathrm{hr}$, and $400 \mathrm{ml}$ every $4 \mathrm{hr}$, respectively, by one of the ICU staff members for three days. The only difference was in the time interval of feeding in each group, which was done in order to reach an equal volume in all three groups after $24 \mathrm{hr}$. In each feeding group (2-, 3-, or 4-hr), the intolerance complications were checked and recorded for 3 days according to the checklist by another staff member who was unaware of the patients' group membership, in order to blind the study. The first author (the researcher) was aware of the patients' grouping.

In this study, intolerance refers to any kind of complications of regurgitation, diarrhea, or high gastric residual volume during the intervention. Regurgitation means a visible exit of stomach contents out of the mouth without energy expenditure [23-25]. Diarrhea was defined as watery stools three or more times with a weight of $200-250 \mathrm{~g} /$ day $[23,26,27]$, and high gastric residual volume refers to the aspiration of more than $150 \mathrm{ml}$ of patients' stomach contents using a $60-\mathrm{ml}$ syringe [3]. The remaining volume of the stomach before any time of feeding as well as instances of regurgitation or diarrhea were recorded at the end of each shift.

\section{Ethical consideration}

The study was approved by the Research Ethics Committee of Hamadan University of Medical Sciences (no. p/16/35/9/6169) and recorded in the Iranian Registry of Clinical Trials (IRCT) database (no. IRCT2014081718832N1). Also, this study was conducted in accordance with the ethical principles provided by the Declaration of Helsinki and the guidelines of the Iranian Ministry of Health and Medical Education. The purpose of this study was explained to the patients while they were conscious; otherwise, the explanation was provided for their family members and relevant authorities. Then, informed written consent was obtained from them. 


\section{Statistical analysis}

After collecting the data for three days, descriptive and inferential statistical methods were used for the purpose of data analysis. To show the demographic characteristics, descriptive statistics such as frequency distribution tables, means and standard deviations, and - in order to compare feeding groups - inferential statistical tests such as the Kolmogorov-Smirnov test (to determine normal distribution of the variables), the chi-squared test, and analysis of variance (ANOVA) were used in Statistical Package for the Social Sciences (SPSS version 16.0, for Windows). A $p$-value of less than 0.05 was considered significant.

\section{Findings}

According to the results, the mean age of the patients in the 2-, 3-, and 4-hr groups was $51.57 \pm 20.58,59.38 \pm 21.68$, and $51.43 \pm 19.73$ years, respectively. The breakdown be gender was as follows: there were 17 male patients $(81 \%)$ and 4 female patients (19\%) in the 2-hr group, 14 men (66.7\%) and 7 women (33.3\%) in the 3-hr group, and 19 men (90.5\%) and 2 women (9.5\%) in the 4-hr group. In terms of reason for hospitalization, 36 patients (57.1\%), 11 patients (17.5\%), and 16 patients $(25.4 \%)$ were hospitalized in the ICU due to trauma, neurological problems, or respiratory problems in the 2-, 3-, and 4-hr groups, respectively. The patients' mean GCS score was 6.68 and their mean Apache score was 17.9. At the time of intervention, $90.4 \%$ and $57.1 \%$ of the patients were administered antibiotics and narcotics, respectively. Patients in all three groups had similar demographic and clinical characteristics and had received the same drugs $(p>0.05)$ (Table 1$)$.

In terms of feeding complications, regurgitation was seen in a total of 27 patients (42.9\%), of whom 14 (66.7\%), 8 (38.1\%), and 5 patients $(23.8 \%)$ were fed at intervals of 2,3 , and 4 hours,

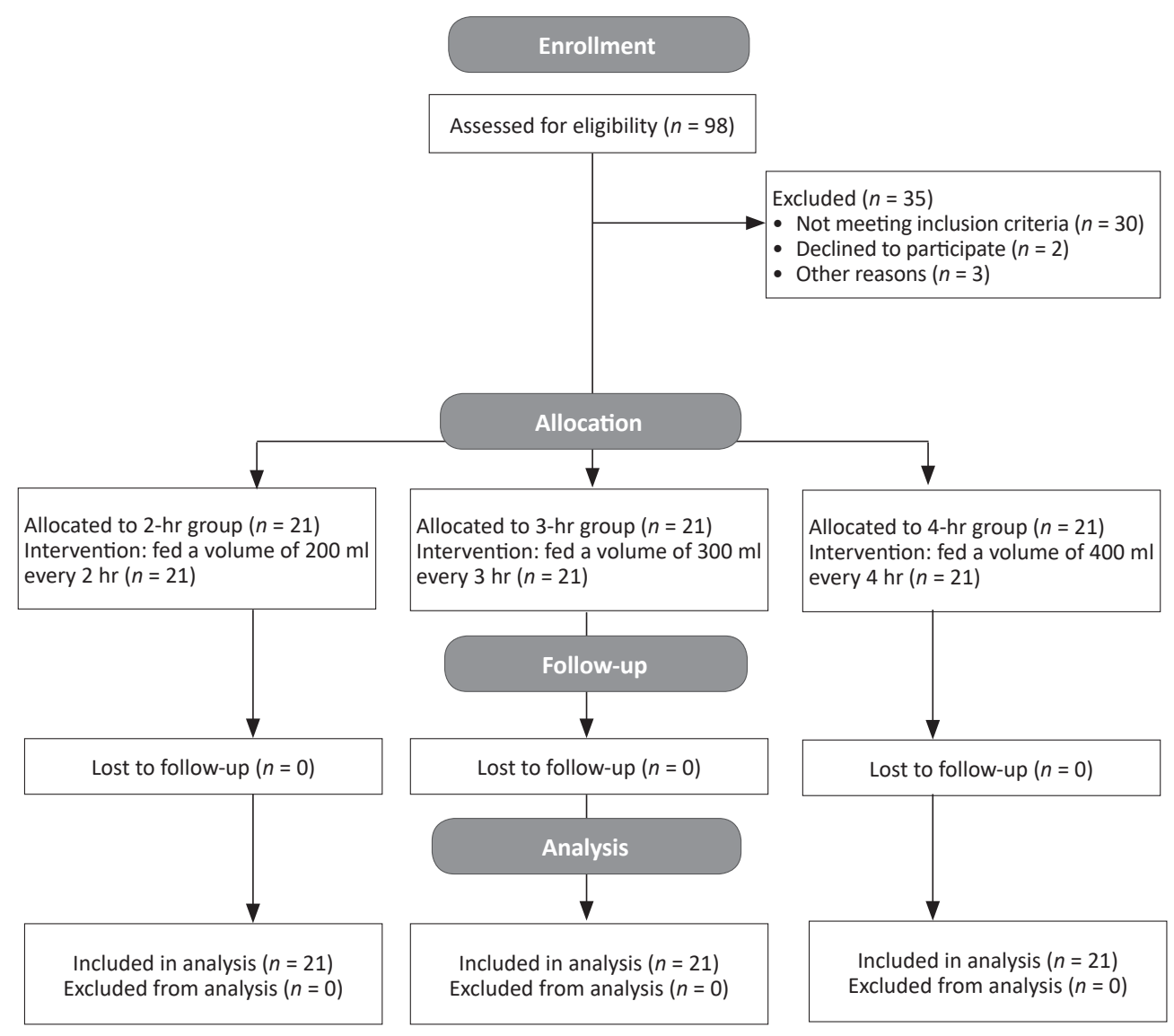

Figure 1. Diagram of enrollment, allocation, follow-up, and analysis of the patients

\begin{tabular}{|c|c|c|c|c|}
\hline Variable & 2-hr group $(n=21)$ & 3-hr group $(n=21)$ & 4-hr group $(n=21)$ & $p$ \\
\hline $\begin{array}{l}\text { Age (years): } \\
\text { Mean } \pm \text { SD } \\
\end{array}$ & $51.57 \pm 20.58$ & $59.38 \pm 21.68$ & $51.43 \pm 19.73$ & 0.360 \\
\hline \begin{tabular}{|l|} 
Sex: $n(\%)$ \\
Male \\
Female \\
\end{tabular} & $\begin{array}{l}17(81) \\
4(19) \\
\end{array}$ & $\begin{array}{l}14(66.7) \\
7(33.3) \\
\end{array}$ & $\begin{array}{l}19(90.5) \\
2(9.5) \\
\end{array}$ & 0.194 \\
\hline $\begin{array}{l}\text { GCS score } \\
\text { Mean } \pm \text { SD }\end{array}$ & $6.62 \pm 2.44$ & $6.38 \pm 2.27$ & $7.05 \pm 2.44$ & 0.698 \\
\hline $\begin{array}{l}\text { APACHE } 2 \text { score } \\
\text { Mean } \pm \text { SD }\end{array}$ & $17.10 \pm 5.19$ & $18.57 \pm 4.61$ & $18.05 \pm 5.74$ & 0.649 \\
\hline $\begin{array}{l}\text { Hospitalization causes: } n(\%) \\
\text { Trauma } \\
\text { Neurological problems } \\
\text { Respiratory problems }\end{array}$ & $\begin{array}{l}15(71.4) \\
3(14.4) \\
3(14.4)\end{array}$ & $\begin{array}{l}8(38.1) \\
5(23.8) \\
8(38.1)\end{array}$ & $\begin{array}{l}13(61.9) \\
3(14.4) \\
5(23.8)\end{array}$ & 0.284 \\
\hline
\end{tabular}




\begin{tabular}{|c|c|c|c|c|}
\hline Variable & 2-hr group $(n=21)$ & 3-hr group $(n=21)$ & 4-hr group $(n=21)$ & $p$ \\
\hline $\begin{array}{l}\text { Drug intake: } n \text { (\%) } \\
\text { Antibiotics } \\
\text { Inotropics } \\
\text { Narcotics } \\
\text { Antacids }\end{array}$ & $\begin{array}{l}19(90.5) \\
1(4.8) \\
14(66.7) \\
20(95.2)\end{array}$ & $\begin{array}{l}19(90.5) \\
3(14.3) \\
10(47.6) \\
18(85.8)\end{array}$ & $\begin{array}{l}20(95.2) \\
1(4.8) \\
12(57.1) \\
21(100)\end{array}$ & \begin{tabular}{|l|}
1 \\
0.605 \\
0.459 \\
0.311
\end{tabular} \\
\hline
\end{tabular}

\begin{tabular}{|c|c|c|c|c|c|}
\hline Variables & $\begin{array}{l}\text { 2-hr group } \\
(n=21)\end{array}$ & $\begin{array}{l}\text { 3-hr group } \\
(n=21)\end{array}$ & $\begin{array}{l}\text { 4-hr group } \\
(n=21)\end{array}$ & $\begin{array}{l}\text { Pearson chi- } \\
\text {-squared test value }\end{array}$ & $p$ \\
\hline $\begin{array}{l}\text { Regurgitation: } \\
\text { No: } 36 \text { (57.1\%) } \\
\text { Yes: } 27 \text { (42.9\%) }\end{array}$ & $\begin{array}{l}7(33.3 \%) \\
14(66.7 \%) \\
\end{array}$ & $\begin{array}{l}13(61.9 \%) \\
8(38.1 \%)\end{array}$ & $\begin{array}{l}16(76.2 \%) \\
5(23.8 \%)\end{array}$ & 8.167 & 0.017 \\
\hline $\begin{array}{l}\text { Diarrhea: } \\
\text { No: } 41 \text { (65.1\%) } \\
\text { Yes: } 22(34.9 \%)\end{array}$ & $\begin{array}{l}13(61.9 \%) \\
8(38.1 \%) \\
\end{array}$ & $\begin{array}{l}11(52.4 \%) \\
10(47.6 \%) \\
\end{array}$ & \begin{tabular}{|l|}
$17(81 \%)$ \\
$4(19 \%)$ \\
\end{tabular} & 3.911 & 0.141 \\
\hline $\begin{array}{l}\text { Gastric residual } \\
\geq 150 \mathrm{ml} \\
\text { No: } 37 \text { (58.7\%) } \\
\text { Yes: } 26(41.3 \%)\end{array}$ & $\begin{array}{l}8(38.1 \%) \\
13(61.9 \%)\end{array}$ & $\begin{array}{l}13(61.9 \%) \\
8(38.1 \%)\end{array}$ & $\begin{array}{l}16(76.2 \%) \\
5(23.8 \%)\end{array}$ & 6.418 & 0.040 \\
\hline
\end{tabular}

respectively. Also, the chi-squared test revealed a statistically significant difference among the three groups $(p=0.017)$. Diarrhea was observed in 22 patients $(34.9 \%)$, of whom 8 (38.1\%), $10(47.6 \%)$, and 4 patients (19\%) were fed at intervals of 2, 3, and 4 hours, respectively; the chi-squared test did not reveal any statistically significant difference among the three groups ( $p$ $=0.194)$. Finally, high gastric residual volume was observed in 26 patients (41.3\%), of whom $13(61.9 \%), 8(38.1 \%)$, and 5 patients (23.8\%) were fed at intervals of 2,3 , and 4 hours, respectively. A chi-squared test revealed a statistically significant difference among the three groups $(p=0.04)$ (Table 2$)$.

\section{Discussion}

Statistical tests for comparing the selected complications in the three feeding groups revealed a statistically significant difference between them in terms of the occurrence of regurgitation ( $p=0.017)$ and high gastric residual volume $(p=0.04)$. In terms of suffering from diarrhea, however, the complication was more observed in the 3-hr group more than in the other groups, but the difference was not statistically significant ( $p=$ 0.194).

In this study, there was a statistically significant difference among the three groups in occurrence of regurgitation and high gastric residual volume. There was no significant difference in the incidence of diarrhea. In terms of feeding tolerance status, the patients fed at 4-hr intervals were at a minimal level. Nevertheless, some studies have shown that feeding intolerance is a complication which is more prevalent in bolus feeding than other methods. In Zeraatkari et al. study, patients tolerate the continuous method better than the bolus method [28]. However, the results of a study by MacLeod et al. which compared continuous and intermittent feeding in critically ill trauma patients showed that the patients receiving intermittent feeding every $4 \mathrm{hr}$ reached the target caloric intake faster than the patients undergoing continuous feeding; also, this feeding method is simpler than the continuous method, while their outcomes are similar [29].

In a study from Egypt by Mohamed et al., which was conducted on the effect of two tube feeding programs on bacterial colonization in the stomach, intermittent feeding every $4 \mathrm{hr}$ was found to be a good way to feed critically ill patients because it was able to prevent the development of bacterial colonies in the stomach [30]. A study by Kadamani et al. compared the effect of two feeding methods - bolus and continuous - on the occurrence of aspiration and gastrointestinal complications and found that there was no statistically significant difference in the feeding method in terms of the incidence of diarrhea, vomiting, or gastric residual volume $(p<0.05)$ [15].

In the present study, regurgitation occurred in $42 \%$ of the patients, which was consistent with the results of Reitnam et al. [31]. Also, diarrhea was found in $35 \%$ of our patients and the statistical tests showed no difference among the three feeding groups in the incidence of this complication, a finding which is consistent with studies by Montejo et al. [32] and Lee and Auyeung [33]. Serpa et al. found that high gastric residual volume occurred in $46.6 \%$ of the patients undergoing tube feeding, though there was no significant difference among the feeding groups in terms of incidence of high gastric residual volume [34]. The results of this study were consistent with our study when it comes to high gastric residual volume.

The results of these studies are sometimes consistent with our results. It seems that the cause of these differences and contradictions can be due to differences in the study groups, nutritional support, and follow-up period. Since nursing practices such as proper nutrition in ICU require adequate and appropriate training, therefore, the quality of training to nursing staff could be an important factor in the difference between the results of studies $[35,36]$.

\section{Limitations of the study}

The limitations of this study were the small sample size and the short follow-up period, as well as the fact that the intervention took place in a limited clinical setting, which could reduce the generalizability of the findings. Therefore, it is recommended to perform additional studies and compare different feeding methods in other wards, with a larger sample size and a longer follow-up period.

\section{Conclusions}

Our study showed that the patients in the ICU who underwent the feeding program using the bolus method at an interval of $4 \mathrm{hr}$ had better feeding tolerance. Therefore, this interval can be used with patients who are fed by the bolus method but cannot tolerate it. This interval can replace the 3 -hr feeding interval which is currently used in ICUs. This finding may be useful for all ICU nurses as well as patients who require tube feeding at home, including stroke and cancer patients, in order to prevent aspiration and its complications. 
Acknowledgments. This study was based on findings of an MSc thesis in critical care nursing approved by Hamadan University of Medical Sciences, Hamadan, Iran (Research number: 9308063696). We express our sincere appreciation to the uni- versity's vice chancellor for approving and funding this thesis, as well as the respectable ICU staff of Besat Hospital of Hamadan city and all the patients and their families who graciously assisted us in conducting this project.

Source of funding: The research was supported by grants from the Hamadan University of Medical Sciences, Hamadan, Iran. Conflicts of interest: The authors declare no conflicts of interest.

\section{References}

1. Keller HH, McCullough J, Davidson B, et al. The Integrated Nutrition Pathway for Acute Care (INPAC): building consensus with a modified Delphi. Nutr J 2015; 14(1): 63.

2. Taylor BE, McClave SA, Martindale RG, et al. Guidelines for the provision and assessment of nutrition support therapy in the adult critically ill patient: Society of Critical Care Medicine (SCCM) and American Society for Parenteral and Enteral Nutrition (ASPEN). Crit Care Med 2016; 44(2): 390-438.

3. Btaiche IF, Chan L-N, Pleva M, et al. Critical illness, gastrointestinal complications, and medication therapy during enteral feeding in critically ill adult patients. Nutr Clin Pract 2010; 25(1): 32-49.

4. Wright-Myrie D, Kahwa E, Dover-Roberts D. Nutrition in critical illness: critical care nurses' knowledge and skills in the nutritional management of adults requiring intensive care - a review of the literature. Caribbean Journal of Nursing 2013; 1: 49-55.

5. Wischmeyer PE. Malnutrition in the acutely ill patient: is it more than just protein and energy? S Afr J Clin Nutr 2011; 24(3): S1-S7.

6. Barr J, Hecht M, Flavin KE, et al. Outcomes in critically ill patients before and after the implementation of an evidence-based nutritional management protocol. Chest 2004; 125(4): 1446-1457.

7. Roynette C, Bongers A, Fulbrook P, et al. Enteral feeding practices in European ICUs: a survey from the European federation of critical care nursing associations (EfCCNa). ESPEN 2008; 3(2): e33-e39.

8. Marshall AP, West SH. Enteral feeding in the critically ill: are nursing practices contributing to hypocaloric feeding? Intensive Crit Care Nurs 2006; 22(2): 95-105.

9. Araújo-Junqueira L, De-Souza DA. Enteral nutrition therapy for critically ill adult patients; critical review and algorithm creation. Nutr Hosp 2012; 27(4): 999-1008.

10. Gungabissoon U, Hacquoil K, Bains $\mathrm{C}$, et al. Prevalence, risk factors, clinical consequences, and treatment of enteral feed intolerance during critical illness. JPEN J Parenter Enteral Nutr 2015; 39(4): 441-448, doi: 10.1177/0148607114526450.

11. Bourgault AM, Ipe L, Weaver J, et al. Development of evidence-based guidelines and critical care nurses' knowledge of enteral feeding. Crit Care Nurs 2007; 27(4): 17-29.

12. O'Leary-Kelley CM, Puntillo KA, Barr J, et al. Nutritional adequacy in patients receiving mechanical ventilation who are fed enterally. Am J Crit Care 2005; 14(3): 222-231.

13. Reintam A, Parm P, Kitus R, et al. Correction: gastrointestinal failure score in critically ill patients: a prospective observational study. Crit Care 2008; $12: 435$, doi: $10.1186 / \mathrm{cc} 7135$.

14. Stroud M, Duncan H, Nightingale J. Guidelines for enteral feeding in adult hospital patients. Gut 2003; 52(Suppl. 7): vii1-vii12.

15. Kadamani I, Itani M, Zahran E, et al. Incidence of aspiration and gastrointestinal complications in critically ill patients using continuous versus bolus infusion of enteral nutrition: a pseudo-randomised controlled trial. Aust Crit Care 2014; 27(4): 188-193.

16. Bowling TE, Cliff $B$, Wright JW, et al. The effects of bolus and continuous nasogastric feeding on gastro-oesophageal reflux and gastric emptying in healthy volunteers: a randomised three-way crossover pilot study. Clin Nutr 2008; 27(4): 608-613.

17. Büyükçoban S, Akan M, Koca U, et al. Comparison of two different enteral nutrition protocol in critically ill patients. Turk J Anaesthesiol Reanim 2016; 44(5): 265-269.

18. Mosazadeh S, Khaleghdoost Mohammadi T, Hasavari F, et al. Comparing the chance of occurrence of respiratory aspiration between two tube feeding methods of intermittent bolus and intermittent drip bag. J Crit Care Nurs 2012; 5(1): 11-16.

19. Reignier J, Mercier E, Le Gouge A, et al. Effect of not monitoring residual gastric volume on risk of ventilator-associated pneumonia in adults receiving mechanical ventilation and early enteral feeding: a randomized controlled trial. JAMA 2013; 309(3): 249-256.

20. Kompan L, Vidmar G, Spindler-Vesel A, et al. Is early enteral nutrition a risk factor for gastric intolerance and pneumonia? Clin Nutr 2004; 23(4): 527-532.

21. Luft VC, Beghetto MG, de Mello ED, et al. Role of enteral nutrition in the incidence of diarrhea among hospitalized adult patients. Nutrition 2008; 24(6): 528-535.

22. McClave SA, Taylor BE, Martindale RG, et al. Guidelines for the provision and assessment of nutrition support therapy in the adult critically ill patient Society of Critical Care Medicine (SCCM) and American Society for Parenteral and Enteral Nutrition (ASPEN). JPEN 2016; 40(2): 159-211.

23. Blaser AR, Malbrain ML, Starkopf J, et al. Gastrointestinal function in intensive care patients: terminology, definitions and management. Recommendations of the ESICM Working Group on Abdominal Problems. Intensive Care Med 2012; 38(3): 384-394.

24. Steinbrook RA, Garfield F, Batista SH, et al. Caffeine for the prevention of postoperative nausea and vomiting. J Anaesthesiol Clin Pharmacol 2013; 29(4): 526-529.

25. Yavuz MS, Kazancı D, Turan S, et al. Investigation of the effects of preoperative hydration on the postoperative nausea and vomiting. Biomed Res Int 2014; 302747, doi: 10.1155/2014/302747.

26. Jack L, Coyer F, Courtney M, et al. Diarrhoea risk factors in enteral tube fed critically ill patients: a retrospective audit. Intensive Crit Care Nurs 2010; 26(6): 327-334.

27. Makic MBF. Management of nausea, vomiting, and diarrhea during critical illness. AACN 2011; 22(3): 265-274.

28. Zeraatkari K, Soltani H, Jaberi A, et al. Continuous method of enteral feeding was better tolerated in SICU patients than bolus method: A-691. EJA 2004; 21: 170.

29. MacLeod JB, Lefton J, Houghton D, et al. Prospective randomized control trial of intermittent versus continuous gastric feeds for critically ill trauma patients. J Trauma 2007; 63(1): 57-61.

30. Mohamed WY, abdel Mageed E, Mehany MM, et al. The effect of two schedules of intermittent enteral feeding on the development of gastric colonization. JEP 2013; 4(18): 151-158.

31. Reintam A, Parm P, Kitus R, et al. Gastrointestinal symptoms in intensive care patients. Acta Anaesthesiol Scand 2009; 53(3): 318-324.

32. Montejo JC, Grau T, Acosta J, et al. Multicenter, prospective, randomized, single-blind study comparing the efficacy and gastrointestinal complications of early jejunal feeding with early gastric feeding in critically ill patients. Crit Care Med 2002; 30(4): 796-800. 
33. Lee JSW, Auyeung TW. A comparison of two feeding methods in the alleviation of diarrhoea in older tube-fed patients: a randomised controlled trial. Age Ageing 2003; 32(4): 388-393.

34. Serpa LF, Kimura M, Faintuch J, et al. Effects of continuous versus bolus infusion of enteral nutrition in critical patients. Revista do Hospital das Clinicas 2003; 58(1): 9-14.

35. Oshvandi K, Amini S, Moghimbeigi A, et al. The effect of spiritual care on death anxiety in hemodialysis patients with end-stage of renal disease: a randomized clinical trial. Hayat 2018; 23(4): 332-344.

36. Bikmoradi A, Zafari A, Oshvandi $\mathrm{K}$, et al. Effect of progressive muscle relaxation on severity of pain in patients with multiple sclerosis: a randomized controlled trial. Hayat 2014; 20(1): 26-37.

Tables: 2

Figures: 1

References: 36

Received: 8.05.2019

Reviewed: 14.05 .2019

Accepted: 6.10 .2019

Address for correspondence:

Samaneh Sadeghi-Hedayat, PhD, Assoc. Prof.

School of Nursing and Midwifery

Hamadan University of Medical Sciences

Hamadan

Iran

Tel.: +98 8138271145

E-mail: mrerazavi@yahoo.com 